Témoigner

Getuigen
Témoigner. Entre histoire et mémoire

Revue pluridisciplinaire de la Fondation Auschwitz

$125 \mid 2017$

Histoire et mémoire de la persécution des

homosexuel-le's par les nazis

\title{
Het militante LGBT-milieu en deportatie op grond van homoseksualiteit
}

Een sociologie van de gedachtenis in een engagementscontext

L'espace militant LGBT et la déportation pour motif d'homosexualité. Pour une

sociologie de la mémoire en contexte d'engagement

\section{Sam Seydieh}

Traducteur : Gorik de Henau et Anneleen Spiessens

\section{(2) OpenEdition}

Journals

\section{Édition électronique}

URL : https://journals.openedition.org/temoigner/6530

DOI : 10.4000/temoigner.6530

ISSN : 2506-6390

Cet article est une traduction de :

L'espace militant LGBT et la déportation pour motif d'homosexualité - URL : https:// journals.openedition.org/temoigner/6504 [fr]

\section{Éditeur :}

Éditions du Centre d'études et de documentation Mémoire d'Auschwitz, Éditions Kimé

Édition imprimée

Date de publication : 1 octobre 2017

Pagination : 108-117

ISBN : 978-2-930953-01-4

ISSN : 2031-4183

Référence électronique

Sam Seydieh, «Het militante LGBT-milieu en deportatie op grond van homoseksualiteit», Témoigner. Entre histoire et mémoire [Online], 125 | 2017, Online op 24 décembre 2021, geraadpleegd op 04 février 2022. URL: http://journals.openedition.org/temoigner/6530 ; DOI: https://doi.org/10.4000/temoigner. 6530 


\section{Het militante LGBT-milieu en deportatie op grond van homoseksualiteit}

\section{Een sociologie van de gedachtenis in een engagementscontext}

deportatie van homoseksuelen ter sprake brengen is van bijzondere betekenis in het militante LGBT-milieu in Frankrijk. De kwestie heeft namelijk een aantal acties en uitspraken uitgelokt in de loop van de geschiedenis van deze bewegingen - achtereenvolgens als 'homoseksueel', 'gay en lesbisch' en 'LGBT' omschreven - en op die manier mee gestalte gegeven aan het engagement voor de homoseksuele zaak. Welke betekenis krijgt het oorlogsverleden binnen dit engagement? Welke dialectische verhouding ontstaat tussen individu en collectief? Deze algemene vragen vormden de basis van het onderzoek dat ik tussen 2009 en 2016 verrichtte in het raam van mijn proefschrift sociologie (Seydieh 2016). Mijn onderzoek, empirisch van inslag, was meer bepaald gebaseerd op biografische interviews met 22 activisten $(\mathrm{m} / \mathrm{v}$ ) afkomstig uit diverse generaties activisten en verenigingen. Ze hebben gemeen dat ze zich in de loop van hun militante carrière hebben ingezt tijdens collectieve acties die betrekling acties die betrekkin hadden het deportatieverleden. Het onderzoek onvat ook twee andere soorten materiaal: enerzijds een reeks observaties tijdens herdenkingsplechtigheden en verenigingsactiviteiten en anderzijds historische documenten, onder andere uit het militante archief. Voortbouwend op dit onderzoek en het materiaal dat ik tijdens a die jaren heb verzameld zal ik in mijn bijdrage bespreken hoe het deportatieverleden wordt verbeeld, gedragen en betekenis krijgt in militante kringen.

Ik voer geen onderzoek naar strategieën en instrumentalisering, en zal dus ook niet verwijzen naar begrippen als 'abus de la mémoire' (misbruik van de herinnering, Todorov 1995) of 'concurrence des victimes' (concurrentie tussen slachtoffers, Chaumont 1997). Mijn aandacht zal daarentegen uitgaan naar de mensen zelf en de manier warop zij zich inschrijven in verchillende sociale milieus (Gensburger de 2002, 2008; 2014; Ger zo alisering en het doorgeven van kennis, begrippen en percepties betreffende het verleden. Bovendien hebben militanten een lange weg afgelegd om uiteindelijk de zaken uit het verleden bespreekbaar en publiceerbaar te maken, met name de bestraffing van homoseksuelen en hun deportatie naar de concentratiekampen. Het militante milieu lijkt in dit opzicht een 'parallel discursief strijdperk' (Fraser \& Valenta 2001,138) waarin de 'ruimte van het zegbare' (Pollak 1986) groter wordt en discriminatie-ervaringen van gays en lesbiennes op verschillende momenten in de geschiedenis uitspreekbaar worden. ${ }^{1}$

Activisten beginnen materiaal over homoseksuele deportatie te verzamelen in een tijd waarin dat feit nog geen deel uitmaakt van het publieke verhaal over de Tweede Wereldoorlog en de naziperiode in Frankrijk. Hun werk om dat verleden toch in beeld te brengen steunt op twee grote pijlers. Een eerste is een sporenonderzoek waarbij verhalen van overlevenden worden verzameld; een tweede is de organisatie van tentoonstellingen, debatten en colloquia, filmvertoningen, voorstellingen en radio-uitzendingen die activisten zelf, maar ook een ruimer publiek, bewust moeten maken van de problematiek. Beide pijlers vormen de basis voor de collectieve acties waarbij vanaf de jaren tachtig wordt geijverd om te mogen deelnemen aan de Franse plechtigheden in het raam van de Journée nationale du souvenir des victimes ethéros de la déportation [Nationale dag ter herinnering van de slachtoffers en helden van

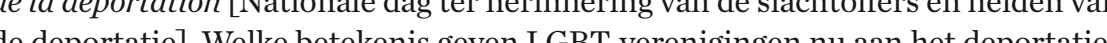
verleden in deze context van engagement en activisme?

\section{KENMERKEN VAN MILITANTE SOCIALISERIN} BINNEN HET LGBT-VERENIGINGSLEVEN

Willen we de kenmerken schetsen van militante socialisering binnen het LGBT-verenigingsleven, moeten we eerst en vooral aangeven waarom de ondervraagden überhaupt bij een LGBT-vereniging terecht zijn gekomen. Tot de aangehaalde redenen behoren steevast de volgende twee: het verlangen om mensen te ontmoeten met wie ze een bepaalde identiteitsopvatting gemeen hebben en de wil om deel te nemen aan specifieke socialiseringsvormen. Bijna alle ondervraagden stellen dat ze zich tot een vereniging wendden om zich via niet-heteroseksuele groepsvorming als 'gay, lesbisch of trans"' te doen gelden. Het verloop van het socialiseringsproals 'gay, lesbisch of trans"' te doen gelden. Het verloop van het socialiseringspro-
ces is nauw verbonden met de mogelijkheden die dergelijke verenigingen bieden: ces is nauw verbonden met de mogelijkheden die dergelijke verenigingen bieden: het voorzien in identificatiemodellen, het construeren van cultureel-historische 2003,25). De voornaamste reden om toevlucht te zoeken tot militante organisaties is dus, volgens de ondervraagden zelf, hun zoektocht naar een ander soort relaties en socialiseringsvormen gebaseerd op activisme. Los van de waarde die de betrokken individuen aan deze of sene actie of activiteit hechten en ongeacht of ze daar voor feen (goed) beeld van hebben, dragt het behoren tot een LGBT-collectief actiefbij tothun actief ijtothident.
(1) Die ervaringen van bestraffing
en discriminatie bereikten de N van bestrafting
ereikten de
hetet moment dat activisten denkcategorieën

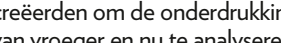
Ik denk daarbij vooral aan de woordenschat die ingang vond
bijhet $F H A R$ (Front $H$ voseswe d'Action Révolutionnaire).
Een mooi voorbeeld daarvent is 'antihomoseksueel racisme' "FHAR 1971), later vervangen door benadrukt door Florence Tamagne de coming-out' van Pierre Seel, tot op vandaag de enige Fransman die heeft getuigd over zijn opslutiting door de nazis op grond van tot november 1941 geinterneerd in het kamp Schirmeck en trad confronteerde activisten met de levendige herinnering aan een gebeurtenis waarvan ze
nauweliks besef hadden. Zijn verhaal werd opgetekend door Bitoux, twee Parijse activisten uit de GLH (Groupes de Liberation
Homosexuelle), die beiden ook tot de oprichters van het tijdschrif
Le Gai Pied behoorden. In 1981 getuigde Pierre Seel anoniem tijdens de voorstelling van de vertaling van het boek van Heinz
Heger in Toulouse. In Les hommes de roze driehoek), waarvan de dateert van 1972 , vertelde Heinz aresertatie en opslutiting. Heger was een Oostenrijker die in 1939 vanwege homoseksualitei naar Sachenhausen werd eerste maal dat in Frankrijk een getuigenis werd gepubliceerd
van een homoseksueel over zijn concentratiekampervaring, en
het bood Pierre Seel een unieke kans om zijn verhaal te doen be 2002, 198)

(2) Voor een discussie over het Wittig (2001), Butler (2005) en 
militante kringen de geschiedenis wordt doorgegeven, welke betekenis bepaalde feiten krijgen, en welke herinnering zo tot stand komt.

\section{OVERDRACHTIN EEN HETEROSEKSISTISCHE CONTEXT:}

DE ROL VAN MILITANTE BEWEGINGEN

In een ruimer perspectief gaan militanten ervan uit dat overdracht in de primaire socialiseringsfase (familiesfeer, school) vol heterocentrische referenties zit. De ervaringen van gays, lesbiennes en transgenders* krijgen daardoor geen plaats in het algemene kennis- en referentiekader. Anders gezegd stoelt het werk van activisten op 'de ervaring van vervreemding tegenover de heterogenormeerde wereld' visten op 'de ervaring van vervreemding tegenover de heterogenormeerde wereld
(Broqua 2005, 190), die kenmerkend is voor het identiteitsvormingsproces van (Broqua 2005, 190), die kenmerkend is voor het identiteitsvormingsproces van
gays, lesbiennes en transgenders*. Die ervaring is op diverse manieren te vinden in het biografische traject van alle ondervraagden en wordt telkens anders verwoord naargelang het sociale profiel van de ondervraagde. De militante socialisering lijkt dus vooral een proces waarbij normen, referenties, interpretatieschema's, rollen en identificatiemodellen worden gedeeld en doorgegeven

Verschillende auteurs hebben in het verleden al onderzoek gevoerd naar wat zij 'het historische of collectieve geheugen van homoseksuelen' noemen (Broqua zij het histo 1997; Celse \& Zaoui 2000). Florence Ta 2005, Cele 1997 Celse \& Z seksuele historische geher [...] directe overdrachtssystemen al te vaak een kortetermijngeheugen blijft, dat doo elke nieuwe generatie van gays en lesbiennes opnieuw wordt uitgevonden of aangeleerd' (Tamagne 2006a, 117). Ze legt meer bepaald nadruk op 'het streven naar gemeenschappelijke referenten' om de inhoud te beschrijven van 'het homoseksuele historische geheugen'. Tegelijk beklemtoont ze dat 'homoseksuelen a prior geen eengemaakte groep vormen noch per definitie een vergelijkbaar "lot" delen (Tamagne 2006a, 117). Als gevolg van het ontbreken van geïnstitutionaliseerde overdrachtsmiddelen worden volgens haar dezelfde vragen over het verleden steed opnieuw gesteld en ontstat bij gays en lesbiennes het gevoel dat ze het verleden (her)ontdekken.

Dat probleem wordt nog scherper als het gaat over de deportatie op grond van homoseksualiteit. De hoofdpersonen van de militante LGBT-sfeer beschouwen dit als een geschikt terrein om het geheugen en de overdracht in stand te houden maar vragen zich tegelijk af in hoeverre dit mogelijk is. Christophe Broqua (2005) en Michel Celse (1997; 2000) hebben onderzoek gedaan naar de de wijze waarop de herinnering aan de deportatie wordt doorgegeven binnen homoseksuele bewegingen, als het voorbeeld bij uitstek van activistische overdracht. De nadruk ligt daarbij, volgens de atueurs, op de overdracht van de 'symbolische inhoud' van ervaringen van andere homoseksuelen uithet verleden De roze driehoek - die is uitoegroeid toteen herkenbar beeld datstat voor die deportatie, toch minstens in militante kringenherm he lectieve geheugen van homoseksuelen'tot stand kwam, en dan meer bepaald binnen een activistische groepssfeer. Volgens Broqua (2005, 265-266) heeft die collectieve omgeving ervoor gezorgd dat wel de 'betekenis' werd doorgegeven van ervaringen van homoseksuelen uit het verleden, maar niet de herinneringen zelf. De betekenissen van de rozen zelf. De e driehoek in de miltante verbeelding, van gesymboliseerde inhoud tot 'pijnlijke verhouding tot een tragisch afwezig verleden' (Celse 1997, 45), reiken duidelijk verder dan alleen maar de deportatiegeschiedenis. Het feit dat zulk symbolisch object wordt ingezet voor de herinneringsoverdracht toont aan hoe zeer die is 'geritmeerd' (Rosoux 2011, 58). Als we er in daad van uitgaan dat de overdracht volgens een variërend ritme verloopt, merken we enerzijds dat de overdracht snel op een aantal grenzen botst die zijn opgelegd door officiële herinneringsmodelen, en anderzijds dat andere sociale actoren een belangrijke rol spelen in het doorgeven van de geschiedenis. Aangezien er weinig ruimten zijn voor de overdracht van kennis en beelden omtrent deportatie en beelden ontront deportatie op grond van homoseksualiteit - al moet dit worden genuanceerd a

naargelang context of periode vormen verenigingen een toegangsweg om het verleden te benaderen. Bovendien
zijn verenigingen ruimten waarin contacten tussen de generaties tot stand kunnen komen.

Voor een beter begrip van de omstandigheden waarin militante overdracht plaatsvindt, is het belangrijk te onderzoeken hoe twee gedachtenisniveaus tot stand komen: de 'geleende' gedachtenis en de militante gedachtenis. Die laatste bestaat ook weer uit twee soorten. De eerste omvat de gedeelde herinneringen an gezamenlijk beleefde onaal verband wordt her onaal verband wordt herdacht. Een tweede soort heeft betrekking op de militante (april 1979). Interlopes werd uitgegeven door de Group 979. 
historische werken, tijdschriften die in de militante sfeer ter zake een referenti zijn geworden, interne publicaties van verenigingen. De perceptie van het deportatieverleden in militante kringen, zo blijkt, is onlosmakelijk verbonden met de herinnering aan de strijd voor de erkenning ervan - een strijd die deel uitmaakt van de meer algemene herinneringscultuur van het verenigingsactivisme (Seydieh 2016).

\section{WISSELWERKING TUSSEN TWEE HERINNERINGSNIVEAUS}

Mensen hebben een geleend geheugen, dat gebaseerd is op wat ze hebben geleerd uit schoolboeken, maar ook op allerlei soorten historische verwijzingen die ze in de loop van hun leven oppikken (Halbwachs 1997, 98-99). De gebeurtenissen tijdens de Tweede Wereldoorlog, een belangrijke episode uit de hedendaagse geschiedenis, maken deel uit van de historische verwijzingen die de ondervraagden zich op diverse manieren hebben eigen gemaakt. Het ene feit weegt echter al zwaarder binnen ons wereldbeeld dan het andere. Mensen weten bijvoorbeeld dat deportatie heeft plaatsgevonden als gevolg van het nazibeleid, maar deportatie op grond van homoseksualiteit in het bijzonder is minder bekend dan andere soorten deportatie. De helft van de ondervraagden uit ons onderzoek zeot dat ze geen weet hadden van homose zich als activist in een LGBT-vereniging engageerden. De anderen waren vooraf wél op de hoogte. Hun kennis over die historische gebeurtenis, door de meesten omschreven als 'heel vaag', is beperkt tot een summiere notie van het bestaan van de 'roze driehoeken'. Interessant genoeg is de belangrijkste bron van informatie de afbeelding van de roze driehoek, he symbool van de deportatie op grond van homoseksualiteit. Die wordt steevast opgelijst in de tabel met concentratiekampmerktekens in Dachau en staat dus gepubliceerd in ontelbare boeken (inclusief schoolboeken) In dat verban is hetboekvan Jean-Baptiste Pattier opmerkelijk, warin ishetboekvan Je auteur de geschiedschrijving over de Tweede Wereldoorlog bestudeert in schoolboeken uit negen Europese landen tussen de jaren vijftig en de jaren 2000. Hij wijst erop dat het historiografische vocabularium voortdurend verandert, net als het discours dat de historische gegevens moet verklaren Aangaande de deportatie van homoseksuelen vermeldt hij de 'vaagheid' van schoolboeken die er 'met moeite iets over zeggen’ (Pattier 2012, 97-98)

Toch kunnen de ondervraagden doorgaans niet zeggen in welke context ze hun kennis precies hebben verworven. We moeten meegeven dat de ondervraagde personen tot verschillende leftijdscategorieën behoren. Ditis net to altijd in een homogene ruimte en binnen vergelijkbare denkkaders. Bijgevolg hadden sommigen al naargelang de periode via het internet toegang tot informatie over homoseksualiteit, onder meer betreffende de nazivervolging van homoseksuelen, terwijl anderen simpelweg niet over dat instrument beschikten. De verhouding tot het verleden en de plaats die homoseksuele deportatie daarin inneemt, hebben dus deels te maken met het kennisniveau van de ondervraagden.

Nochtans wijst Halbwachs erop dat abstracte kennis alleen nog niet uitmondt in gedachtenis, want een historisch begrip is op zichzelf enkel een leeg kader (Habingedacis wachs $1997,120-121$. In de tante sfeerderuintevont herinneringen. Voor het individu dat binneneen verenigingsociale banden aangaat, komt het verleden tot leven dankzij herinneringen van heel uiteenlopende aard. Er zijn bijvoorbeeld de persoonlijke herinneringen van overlevenden van de deportatie, die worden opgerakeld in het bijzijn van activisten of waarvan het opgetekende verslag in militante kringen wordt verspreid. Wie bijvoorbeeld Pierre Seel heeft ontmoet, de enige Franse getuige die met zijn verhaal naar buiten is gekomen, kon zich op emotionele wijze verhouden tot zijn herinneringen. Het opsporen van zulke herinneringen krijgt pas zijn volle betekenis in de militante sfeer, waar ze worden gebruikt als bewustmakingsinstrument.

Op dit gedachtenisniveau vinden we voorts de levendige gedachtenis terug, dus de persoonlijke herinneringen van activisten die een ervaring delen en samen actie hebben gevoerd, meer bepaald tijdens herdenkingsplechtigheden. Het feit dat ze bij hun eerste contacten met andere militanten direct te maken krijgen met deze vorm van gedachtenis vormt voor alle ondervraagden de communicatieve basis om zich vervolgens in te schrijven in twee soorten dynamieken: enerzijds de visie op het verleden zoals die in dat milieu tot stand komt en die grotendeels afhankelijk is van de wijze waarop nieuwelingen de persoonlijke herinneringen interpreteren anderzijds de militante acties die de continuïteit van de twee gedachtenisniveaus verzekeren. De meeste ondervraagden vernemen pas bij hun toetreding tot een deportatie op grond van homoseksualiteit. De active grond van homoseksualiteit.

De 'activistenfilter' heeft een aanzienlijke invloed op de betekenis die de ondervraagden zullen toekennen aan de deportatie. Hun engagement binnen de vereniging verandert dus hun individuele wereldbeeld, want het wordt afgestemd op een aantal ijkpunten van de militante historische gedachtenis. Het 'geheugen van de deportatie op grond van homoseksualiteit' is heel erg gebaseerd op het militante strijdverleden zoals dat vandaag wordt begrepen. In sommige gevallen 'ontdekt' het individu in kwestie het bestaan van homoseksuele deportatie op het moment dat hij of zij contact zoekt met een militante beweging, terwijl anderen vooraf op de hoogte waren maar vervolgens ontdekken wat ditalles 'werkelijk' betekent Het is uiteraard bijzon brinteresantom vast te stellen dat (nieuwe) betekenissent totstand koard dankzij ont inomen ontdekking bevatting en kennis van een historisch feit zijn onlosmakelijk verbon-
(3) Het verhaal van Pierre Seel
(1994) werd opgetekend in samenwerking met de activis Jean Le Bitoux, een van de
pioniers van Mémorial dela Déportation Homosexuelle (opgericht in 1989), de eerste
Franse vereniging die zich Franse vereniging die zich
specifiek bezighoudt met deportatie op grond van homoseksualiteit. De leden
van Oublié.e. de tweede vereniging ter zake
(opgericht in 2003), verzamelde herinneringen en getuigenissen Rudolf Brazda (Schwab 2010)
Rertend van het veral 'de laatste overlevende roze 
Het militante LGBT-milieu e deportatie op grond van
homoseksualiteit (vervolg)

den met de context waarin dat proces plaatsvindt. Er is met andere woorden een verband met het moment waarop nieuwkomers in een vereniging 'begrijpen' hoe activisten die de deporatieherinnering belichamen worden 'behandeld' tijdens een publieke plechtigheid.

Voor nieuwkomers krijgt het verleden dus betekenis vanuit een actuele ervaring. In dat proces is één bepaalde factor doorslaggevend, namelijk het besef dat er een 'militante strijd' wordt geleverd om de homoseksuele deportatie een plaats te geven in de nationale herinneringscultuur Zostellendeondervraggenvastdatbijoficiole (a) begrippen die in deze context telkens opduiken - 'nooit meer', 'tegen het vergeten' - en die de meeste ondervraagden sinds hun schooltijd kennen, worden opnieuw onder de loep genomen en krijgen een andere invulling door hun engagement. Wie zich collectiefinzet om te strijden voor de erkenning van homoseksuele deportatie bij herdenkingen, zo leert ons het traject van de activisten, verandert zijn of haar kijk op het (nationaal, familiaal) verleden. Of ze nu vooraf kennis hadden van de historische feiten of niet, hun geleende geheugen wijzigt hoe dan ook door hun engagement. Voor de meeste ondervraagden is het tijdstip waarop ze aan activisme gaan doen het moment waarop abstracte referenties veranderen in een bron van concrete actie.

Via hun betrokkenheid bij militante acties krijgen de ondervragden een beter zicht op de notie zelf van een 'gedeeld verleden zeggen het verleden van homoseksuelen, homoselsuait nzovoort. Willen ze zich in een collectief inzetten moeten ze een standpunt innemen tegenover het verleden van dat collectief, met alle consequenties voor het heden. Los van de persoonlijke herinneringen van ke herinneringen van levende activisten wordt de militantehistorischegedachtenis doorgegeven als nieuwkomers zich mettertijd vertrouwd maken met standaardwerken binnen het militante milieu. Pamfletten, brochures, nieuwsbrieven, boeken en tijdschriften zijn evenzoveel instruzijn evenzoveel instrumenten om je kennis
aangaande het verleden uit te diepen. Via de toe-eigening van het militante verleden krijgt het begrip 'verleden' een ruimere betekenis. De ondervraagden verwijzen naar voorbeelden van strijd waaraan ze niet zelf hebben deelgenomen maar die ze wel gebruiken als ijkpunt om hun eigen engagement in het heden te situeren.

Door wat we net hebben gezegd over de wisselwerking tussen de geleende herinneringen van ondervraagden en militante herinneringen mag niet de indruk ontstaan dat de visie van personen op het verleden zich beperkt tot die twee gedachtenisniveaus. Om zowel de drifveren van het engagement als de herdenking van het niveaus. O zow de drifveren van het engagement als de herdenking van het verleden te begrijpen moeten ze zich bezinnen over andere gedachtenisniveaus en socialiseringservaringen. We wijzen in het bijzonder op socialisering binnen de familiesfeer en andere militante middens (vakbonden, verenigingen, strijdgroepen). Het leerproces tijdens socialisering binnen de familiesfeer fungeert inderdaad als een 'kennisreserve' (Schütz 1998), terwijl engagement op andere plekken vooral gaat bepalen hoe iemand denkt dat publiek engagement aangaande de herdenking van homoseksuele deportatie er moet uitzien.

\section{BESLUIT}

Wie toetreedt tot een vereniging doorloopt een leerproces vol ontdekkingen maar ook onzekerheid over de mogelijkheden om zich te engageren. Eerst moet maar ook onzekerheid over de mogelijkheden om zich te engageren. Eerst moet een nieuweling zich de geldende regels en gangbare praktijken eigen maken. Dat
gebeurt via relaties en interacties tijdens algemene vergaderingen, bijeenkomsten, gebeurt via relaties en interacties tijdens algemene vergaderingen, bijeenkomsten,
groepsmomenten en acties waarbij andere personen uit de vereniging of het verenigingsleven betrokken zijn. Onderzoek naar het belang van de herdenking van de deportatie moet zich dus voornamelijk richten op een analyse van de intersubjectieve relaties binnen verenigingen. Via hun banden met sleutelfiguren van de militante strijd om erkenning en herinnering gaan nieuwkomers deel uitmaken van de engagementscultuur. De herinnering aan het deportatieverleden kunnen we beschouwen als een essentieel aspect van de acties die de verschillende bewegingen in de loop van de geschiedenis hebben gevoerd. Dat komt omdat die gebeurtenissen belangrijk zijn in het proces van identiteitsvorming. De specifieke strijd voor zichtbaarheid en erkenning van homoseksuele deportatie weet zo veel mensen te mobiliseren omdat er een nauw verband is met hun persoonlijke ervaringen in een heteroseksistische context en met wat velen beschouwen als een geschiedenis van homoseksuele discriminatie. Toch is de 'weerklank' van het verleden in het heden niet vanzelfsprekend of eenduidig. Wie meer te weten komt over homoseksuele deportatie - of dat nu voor of na zijn of haar engagement gebeurt - moet een reeks strategieën aanleren om dat verleden te interpreteren en inzichtelijk te maken. Die interpretatiemechanismen raken vervlecht met het levensverhaal van de ondervraagden, met hun uiteenlopende persoonlijke ervaringen en hun zoektocht naar hun identiteit als gay lesbienne of transiender.

De historische feiten alleen volstaan niet om die identiteit vorm te geven. Het is de manier waarop ze binnen de militante sfeer worden opgetekend en doorgegeven 
Het militante LGBT-milieu e deportatie op grond var

(vervolg)

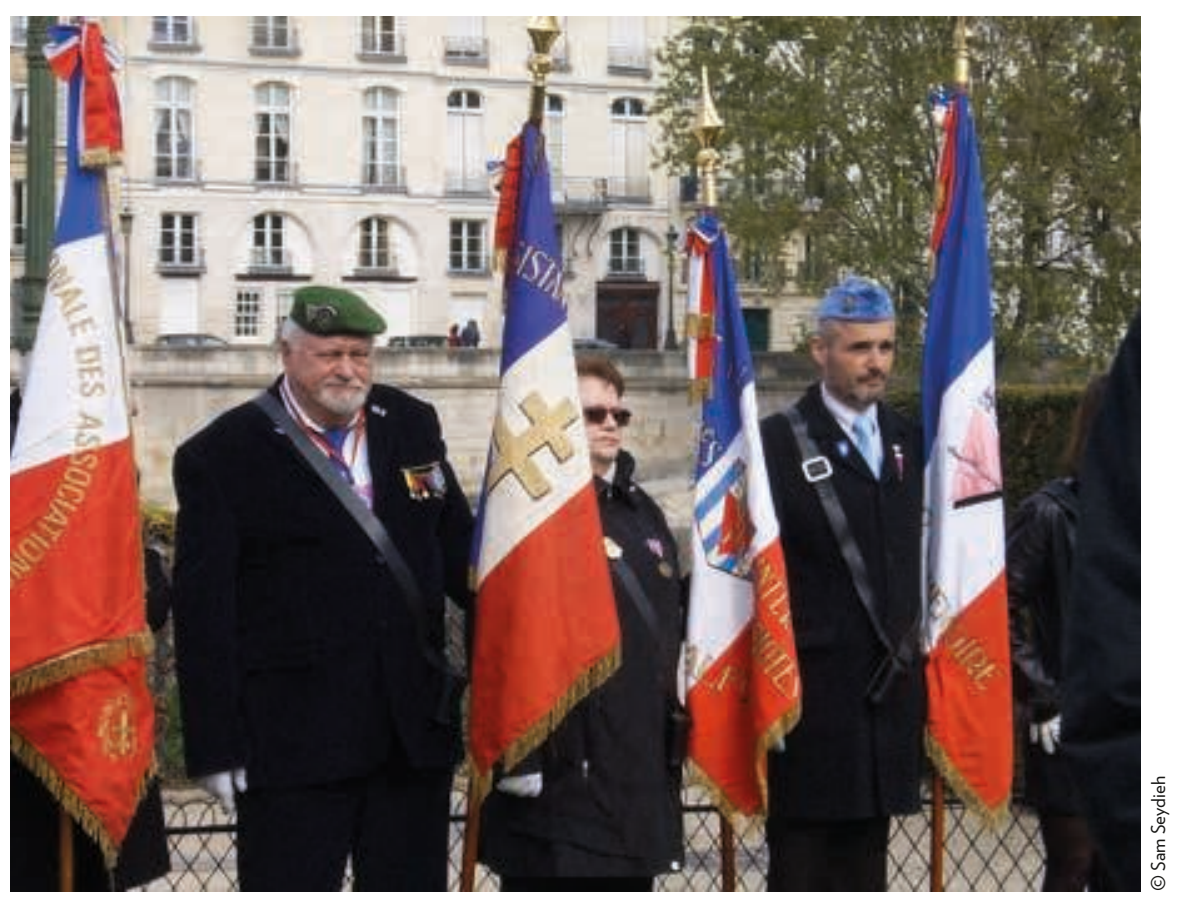

die maakt dat er een bepaalde verhouding ontstaat tussen het individu en de groep, die een motivatie kan zijn om tot actie over te gaan. Verenigingen en activisten beschouwen de herinnering aan dat verleden, zoals die wordt gekoesterd in militante middens, als een antwoord op vele van hun vragen. Dat opent perspectieven mensen geven zin aan hun persoonlijke traject door te verwijzen naar het verleden, terwijl het voor verenigingen het startpunt vormt voor hun acties. De vorm die het engagement aaneemt - deelnemen an een herdenking voorstellingen maken, engagen maken, een leid ë zowel beinvlod door individuele bijdragen. Die dialectiek tussen enerzijds de noodzakelijke groepscontext voor het herdenken en interpreteren van het verleden en anderzijds de individuen die dat verleden een bepaalde zin geven afhankelijk van hun eigen levensloop verklaart het bonte karakter van het engagement in termen van stijl, intensiteit en einddoel. Tot slot is het recht van spreken, of de mogelijkheid om hun homoseksuele ervaring te delen en te benoemen, voor de ondervraagden een verbindend element tussen heden en verleden. Het feit dat gedeporteerde, geïnterneerde en vervolgde homoseksuelen niet over hun lotkonden spreken doet denken aan de weg die homoseksuelen in het algemeen aflegren voor ze zich kunnen uiten, en dan ook nog eens zonder nog eens zonder schaamtegevoel. De herinnering aan het verleden blijft overigens niet beperkt tot

schappelijke omstandigheden die maken dat homoseksualiteit wordt doodgezwegen. Activisten werken strategieën uit om een gebeuren zichtbaar te maken dat gehuld gaat in stilte en door de 'meerderheid' niet wordt begrepen, en proberen op die manier modellen aan te reiken aan wie op zoek is naar figuren en verhalen om in een heteroseksistische wereld vorm te geven aan zijn of haar identiteit.

BIBLIOGRAFIE

- Christophe Broqua, Agir pour ne pas mourir! Act Up, les homosexuels et
le sida, Parijs: Presses de la Fondation Nationale des Sciences Politiques.

-..- \& Pierre-Olivier de Busscher, 'La crise de la normalisation., Expérience et condition sociales de lhomosexualité en Francé,
in Christophe Broqua, France Lert \& Yves Souteyrand (red.). Homosexualite au temps du sidda. Tensions sociales et id dentitaires, Pariss: - Judith Butler, Trouble dans le genre. Le féminisme et la subversion de
lidentité, Parijs: La Découverte. 2005 .

- Michel Celse, 'll parâit que le mouvement gai a cent ans..., Vacarme 3,
1997. 44-47. -.- \& Pierre Zaoui, 'Négation, dénégation: la question des triangles roses', in Philippe Messard (red.), Consciences del la Shooh: Critique des
discours et des représentations, Parijs: Kimé, 2000, 203-222. - Line Chamberland \& Christelle Lebreton, "Réflexions autour de - Line Chamberland \& Christelle Lebreton, 'Réflexions autour de la
notion d'homophobie; succés politique, malaises conceptuels et
application empirique,' Nouvelles Questions Fémininistes $31,2012,27-43$. - Jean-Michel Chaumont, La concurrence des victimes. Génocide,
identité, reconnaissance, Parijs: La Découverte, 1997 .

- FHAR, Rapport contre la normalité, Parijs: Champ libre, 1971. - Nancy Fraser \& Muriel Valenta, 'Repenser la sphère publique: une
contribution à la critique de la démocratie telle quielle existe réellement contribution à la critique
Hermes $31,2001,125-156$

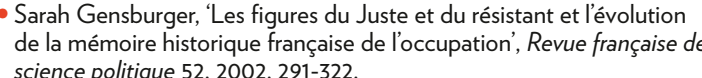
-..., 'Réflexion sur l la notion de "politique de la mémoire", in Michel

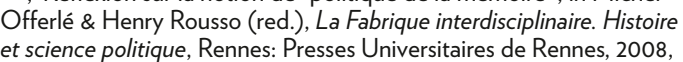
133-147.

-.-., 'Comprendre la multiplication des journées de commémoration
nationale. Etude d'un instrument d'action publique de nature symboliqué, in Charlotte Halpern, Pierre Lascoumes \& Patrick Le Galès 2014, 345-366.

--.- \& Marie-Claire Lavabre, Entre "devoir de mémoire" et "abus de

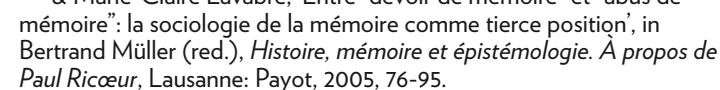

- Maurice Halbwachs, La mémoire collective, Parijs: Albin Michel, 1997. - Heinz Heger, De mannen met de roze driehoek: het verslag van een homoseksueel over zijin gevengenschcha in het concentratiekamp van 1939
tot 1945 [1972]], uit het Duits vertaald door A. J. Gerritsen, Amsterdam:
Pegasus. 1982 .

Marie-Claire Lavabre, 'Usages et més
Critique internationale 7, 2000, 48-57.

-.-., 'De la notion de mémoire à la production des mémoires collectives', in

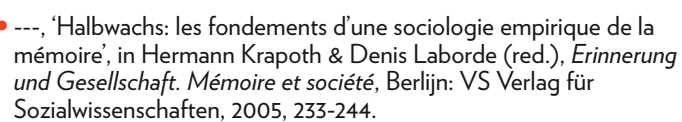

-.-, 'Paradigmes de la mémoire', Transcontinentales 5, 2007, 139-147. - Jean Le Bitoux, Les oubliés de la mémoire, Parijs: Hachette, 2002. - Jean-Baptiste Pattier, Verités officiellles. Comment sécrit 'histoire de la 'Michael Pollak, 'Le témoignage', Actes de la recherche en sciences
sociales 62-63, 1986 3-29. - Valérie Rosoux, 'Mémoire et résolution des conflits. Quelle transmission au
lendemain dune guerre?', in Nathalie Burnay (red.), Transmission, Mémoire
et reconnaissance, Fribourg: Academic Press Fribourg, 2011, 57-80. - Jean-Luc Schwab, Rudolf Brazda. Itinéraire d'un Triangle rose, Parijs. Florent Massot, 2010

- Pierre Seel, Moi, Pierre Seel, déporté homosexuel, Parijs: Calmann-Lévy,
1994. - Sam Seydieh, Déportation pour motif d'homosexualité et mouvement $L G B T$ en France. Evocations du passé: entre engagement
militint et tadre institutionnel, doctoraatsverhandeling in de sociologie, Paris Descartes, 2016.

- Florence Tamagne, 'La construction d'une m
homosexuelle', Controverses 2, 2006, $116-12$.

-..., 'La déportation des homosexuels durant la Seconde Guerre .

. Podorov, Les abus de la mémoire. Pariis: Arléa, 1995.

- Monique Wittig, La pensée straight, Parijs: Balland, 2001 